\title{
LIII.-Observations on the Development of the Cirripedia.
} By Dr. August Krohn*.

[With a Plate.]

The results which we have lately obtained - thanks to the labours of Burmeistert, Spence Bate $\ddagger$, and Darwin $\S$ - upon the development of the Cirripedia are so satisfactory, that we might already congratulate ourselves úpon an insight into the manifold changes passed through by the young animal from its birth to the attainment of its perfect form, if there were not a sensible gap still vacant. It is still unknown by what intermediate steps the larva, which, during the first period of its development, agrees in so many respects with the young forms of the Entomostraca, especially the Copepoda, passes to the subsequent Cypris-like form. During my residence in Funchal, and afterwards at Messina, I was able to obtain some information upon this still unexplained point. Before communicating my observations on this subject, I think it will be necessary in the first place to describe the form presented by the larva during the first period of its development, and then to refer more particularly to individual organs which are peculiar to it in its later Cypris-form.

At a certain stage of development, when the larva has moulted two or three times after its escape from the egg, we distinguish in it a broad body (Vorderleib), frequently truncated in front, and diminishing posteriorly, followed by two slender processes extending backwards (Pl. VII. fig. 1). The superior process has the form of a straight, extended, and often very long spine; the inferior one, which is stouter, runs, gradually tapering, to a forked extremity, and is, especially in the later stages, capable of being bent and extended. I characterize it provisionally as the caudiform appendage $\|$. The body is covered on the dorsal surface with a carapace or shield, the anterior angles of which are produced into two thin horns, furnished with a few curved bristles at the apex ๆ. On the lower surface the body is provided with three pairs of swimming feet, and with a proboscidiform process springing freely from the middle between the last pair. Close behind the anterior margin of the carapace, a small eye, provided with F.L.S.

Translated from Wiegmann's Archiv, 1860, p. 1, by W. S. Dallas,

+ Beiträge zur Naturgeschichte der Rankenfüsser, 1843. 1851.

\$ On the Development of the Cirripedia, Annals, ser. 2. vol, viii. p. 324,

$\$$ Monograph of the subclass Cirripedia, 1851 \& 1854.

II From the figures to Spence Bate's memoir, I cannot but think that this observer regards the spinous process as a prolongation of the carapace next to be mentioned, which is certainly wrong.

Tा Burmeister and Darwin regard these horns as antennæ, but erroneously, as will hereafter appear. 
a prominent lens and enveloped in dark pigment, shines through from the interior of the body. This ocellus rests upon the middle of the anterior margin of a distinctly marked structur $f$ closely applied to the ventral surface, and surrounding the œesophagus like a ring (Pl.VII. fig. 3), which I can regard as nothing. but the central mass of the nervous system or as the œsophageal ring. The swimming feet, of which the foremost pair are simple, the intermediate and hinder pairs divided into two branches, are abundantly beset with long bristles, part of which are simple, part delicately plumose (fig. 2). In the middle of the extremity of the proboscidiform process is the mouth, leading into a narrow œsophagus, which extends through the axis of the process, and penetrates into the body through the orifice of the œesophageal ring. The rest of the alimentary canal passes straight through the body, swells in the middle of its course into a roundish dilatation, and terminates in an anus, situated dorsally at the base of the caudiform appendage (fig. 2 ) *.

In the second period of development, the larva, as is well known, is enclosed in a bivalved carapace or shell, in the same way as the genus Cypris. It possesses two compound eyes and one simple one, and is furnished on the lower surface of the hinder part of the body, corresponding with the thorax of the mature animal, with six pairs of swimming feet divided into two branches. At the extremity of this region of the body there is a short tail-like process (abdomen of Darwin), which is furnished with two appendages resembling the branches of the swimming feet. Two other strongly developed members are particularly worthy of notice; these spring from the fore part of the body, in the vicinity of the compound eyes. With their assistance the larva creeps about, and it is by means of them that it finally attaches itself to foreign bodies, when the time has arrived for its last metamorphosis $\dagger$.

The two compound eyes lie quite laterally close under the

* Leaving out of consideration the horns of the carapace and the spinous process, the larvæ of the Cirripedes consequently agree closely, both in their external and internal structure, with the young forms of the Cyclopida, as these are made known to us by the admirable memoir of Claus (On the Anatomy and Developmental History of the Copepoda, Wiegmann's Archiv, 1858, p. 1). This agreement shows itself not only in the similar number and analogous nature of the swimming feet, but also in the structure of the eye (see Claus, $l . c$. figs. $64 \& 66$ ), in the arrangement of the alimentary tube, and in the presence of a so-called oral hood (Mundkappe), which is to be compared with the proboscidiform process. But the caudiform appendage of the Cirripede-larvæ corresponds with the posterior segment of the Nauplius-form of the Copepod-larvæ, as will appear hereafter.

$\dagger$ Upon this period see the extremely accurate and complete description of Darwin (vol. ii. pp. 110-123). 
corresponding valves of the shell, in the anterior portion of the hody, which, in the Lepadidæ, afterwards becomes for the most 1 irt developed into the peduncle. They consist of a dark mass of pigment, in which several roundish crystalline bodies are deeply immersed, and of an external envelope, which covers the crystalline bodies in the form of a cornea ; they therefore agree in structure with the eye of the Daphniadæ.

The simple eye is situated in the median line, higher up towards the back than the compound eyes, and a little behind them. It is, as will hereafter appear, the ocellus of the previous period. It consists of a firm capsule filled with a mass of blackishbrown pigment, but apparently no longer contains a lens, and is thus reduced to a mere organ for distinguishing light and darkness. In the last metamorphosis it passes into the young Cirripede, and is always, as is well known, readily to be detected even in fully developed Cirripedes, especially the Lepadida.

The six pairs of swimming feet, which are subsequently converted into the cirri, consist of a peduncle, from which the two branches already mentioned are given off; the terminal joint of the latter bears several very long biplumose bristles. The two appendages of the caudal process or abdomen are beset at the extremity with exactly similar bristles.

The two walking or adhering feet consist of four joints, of which the third is dilated into a disk; the very short terminal joint is attached to the upper surface of the disciform joint, and indeed quite to one side and at a right angle (see Darwin, pl. 30. fig. 8). In walking, during which the legs are alternately extended and retracted, the disciform joint presses, like a sucker, so firmly to the object as to enable the animal even to creep up polished surfaces, such as the wall of a glass. By means of the same disciform joints the young animal attaches itself to foreign bodies when it is about to undergo its final metamorphosis *.

After these explanations, I may pass to my own observations.

I have observed the transition to the Cypris-form in two species of larvæ, one of which I met with in various stages of deve-

* As Darwin has already proved, a regular cementation, by means of a tenacious gluey substance issuing from the adhesive disks, takes place during this adhesion. This cement is conveyed to the adhesive disks by two canals (the cement-ducts), which may be traced through the axis of the ambulatory feet as far as two sausage-shaped masses situated in the body, which Darwin regards as the glands preparing the cement (see Darwin, pp. 116 \& 122). Darwin's investigations show further that the cementation goes on uninterruptedly during the growth of the Cirripedia, and that in proportion as the surface of adhesion (the lower extremity of the peduncle in the Lepadidæ, or the base of the shell in the Balanidæ) increases in size, the cement-apparatus also becomes further developed.

Ann.\&. Mag. N. Hist. Ser. 3. Vol. vi. 
lopment during my residence in Madeira. It is probably the young of a Balanide.

In the older larvæ of this kind (fig. 1) the anterior body is o considerable size, and the carapace is furnished at the anterior margin with two moderately long horns, and at the posterior margin with two spines directed obliquely upwards, which are wanting in younger larvæ. The caudiform appendage is armed, about halfway to its apex, with four lateral spines of considerable size arranged in two pairs, and is a good deal thicker than the spinous process, especially in its anterior incrassated half. In still further advanced larvæ the carapace appears enlarged and much arched.

One day a larger and still further developed larva of the same kind was captured; its close examination gave the following results :-The carapace was now so far changed from its former state, that it extended further down, and thus enclosed the body on both sides. The caudiform appendage appeared strongly inflated in its anterior longer portion, reaching somewhat beyond the above-mentioned pairs of spines. On the lower surface of this portion six pairs of processes, arranged close together in a row, could be distinguished through the skin; each of these consisted of a comparatively long peduncle and of two short branches terminating in rounded ends, issuing from it. Close behind the last pair, another much shorter process, with two projections similar to the branches of the longer processes, shone through the skin. Both the projections, as well as the above-mentioned branches, appeared to be set with thin offshoots or filamients, which were recognized as the rudiments of so many setæ. With regard to the signification of these processes I could not long remain in doubt; they were evidently the swimming feet in course of development, and the base of the caudal process the subsequent Cypris-like form. It followed, therefore, that the whole inflated part of the caudiform appendage was to be regarded as the rudiment of the future thorax. On each side, in the same line with the original simple eye, now become larger and enveloped by a very dark pigment, a roundish organ was distinguished, containing several scattered deposits of reddishyellow pigment. The opinion forced itself upon me at once that these two structures could only be the rudiments of the compound eyes, which indeed was soon confirmed, as I succeeded in observing the gradual conversion into the Cypris-form in the same larva.

On the third day after the capture of the larva, I saw the carapace prolonged so far backwards as to form a roof over the entire anterior portion of the caudiform appendage. The simple eye had become still larger, whilst the pigment-deposits in the 
rudiments of the compound eyes appeared more crowded together and of a darker or blackish colour. The swimming feet had become further developed. On the morning of the fourth day I found the animal already metamorphosed, which, as was to be expected, did not take place without a shedding of the previous envelopes of the larva.

Although these observations evidently proved that in the transition to the second period of development the carapace becomes converted into the bivalve shell, and the whole anterior portion of the caudiform appendage into the thorax, it still remained quite uncertain from what parts the ambulatory or adhesive feet might have been produced. I only obtained accurate information upon this point subsequently in Messina, from the larva of another nearly allied species, which was captured in a very far advanced stage, and the metamorphosis of which took place as early as the evening of the same day. From this larva, in the compound eyes of which the individual crystalline bodies imbedded in the pigment-mass were distinctly recognizable, I believe I have ascertained with certainty that the adhesive legs are produced from the anterior pair of swimming feet [in the first stage of the larva]. The end of each of these feet was flattened into a disk, upon which a terminal joint appeared to be seated, exactly in the same way as in the adhesive feet*.

Judging from the above results, the larva of a Lepas observed by Burmeister (l. c. p. 16, tab. 1. figs. $3 \& 4$ ), and regarded both by that naturalist and by Darwin (l. $c$. p. 109) as the representative of a stage of development immediately preceding the Cypris-form, can no longer be taken as such. It is already, as shown by Burmeister's figure, attached by means of the adhesive feet, and possesses a bivalved shell, but differs essentially [from the ordinary form $]$ in having, instead of six, only three pairs of swimming feet, of which the foremost is stated to be undivided. I can consequently regard this larva as nothing but an aborted, or, which is more probable, as a monstrous specimen.

In conclusion, I may call attention to a young Cirripedelarva observed in Messina, probably belonging to a Lepadide. The carapace, as shown in fig. 2 , is pentagonal, and armed on the upper surface with a strong spine, the apex of which is bent backwards, and on the margins with several symmetrical longer

* The opinion of Burmeister and Darwin, that the horns of the carapace become metamorphosed into the adhesive feet ("prehensile antennæ" of Darwin), is consequently erroneous. The horns, as I convinced myself, are thrown off unchanged with the envelope of the larva. What becomes of the two posterior pairs of swimming feet in the change is entirely unknown to me. 
and shorter teeth. The spinous process of the body is of extraordinary length; the caudiform appendage, which is still but little developed, terminates in a pointed extremity bent upwards. The length of the larva is 3 millim.

\section{EXPLANATION OF PLATE VII.}

Fig. 1. Larva, probably of a Balanide, seen from above. Of the swimming feet, only the middle pair and one of the anterior are seen extended: $a$, carapace; $b b$, horns of the carapace; $c$, eye ; $d$, spinous process of the body; $e$, caudiform appendage of the body.

Fig. 2. Very young larva of a Cirripede, probably a Lepadide; from the back : $a$ to $e$, as in fig. 1 ; $f$, alimentary canal.

Fig. 3. A portion of the body of the larva of Lepas anatifera after the first moulting, strongly magnified : $a$, central mass of the nervous system; $b$, ocellus; $c c$, the two horns of the carapace.

LIV.-Note on Psammophis Perroteti, D. \& B. By Dr. Albert Günther.

[With a Plate.]

Duméril and Bibron have omitted several important characters in their description of this remarkable snake, which is a truly intermediate form between Psammophis and Dryophis. One of its most important characters appeared to me to be the keeled scales of the coccygeal region*; but as nothing of it is mentioned by the French herpetologists, I failed to recognize the first specimens which came under my observation, and described them as a new species-Dryophis tropidococcyx. The latter specific name has been chosen with the view of its serving as the name of the genus, if the snake should be considered as a peculiar type. It cannot be referred either to Psammophis or to Dryophis without disturbing the natural characters of those genera; whilst, as a separate genus, it may be placed in the family of Dryophida, the characters being rather more in favour of its relation to this family than to the Psammophida.

\section{Tropidococcyx.}

Habit and physiognomy of Psammophis. Scales smooth, those of the coccygeal region keeled. Rostral shield far produced backwards. A single nasal, pierced by the nostril; posterior nasal and loreal absent, replaced by the anterior and posterior frontals, which are bent downwards on the side of the head. Pupil horizontal (Dryophis). The fifth of the anterior maxillary teeth and the hindmost longest, the latter grooved.

* A similar peculiarity occurs in Aspidura trachyprocta, Cope, and Trachischium, Gthr. 


\section{$2 \mathrm{BHL}$ Biodiversity Heritage Library}

Krohn, August. 1860. "LIII.-Observations on the development of the Cirripedia." The Annals and magazine of natural history; zoology, botany, and geology 6, 423-428.

View This Item Online: https://www.biodiversitylibrary.org/item/19439

Permalink: https://www.biodiversitylibrary.org/partpdf/15725

\section{Holding Institution}

Natural History Museum Library, London

\section{Sponsored by}

Natural History Museum Library, London

\section{Copyright \& Reuse}

Copyright Status: Public domain. The BHL considers that this work is no longer under copyright protection.

This document was created from content at the Biodiversity Heritage Library, the world's largest open access digital library for biodiversity literature and archives. Visit BHL at https://www.biodiversitylibrary.org. 